\title{
Sprawozdanie z działalności Polskiego Towarzystwa Filozoficznego w 2014 roku
}

\section{INFORMACJE OGÓLNE}

\section{A. Struktura i władze PTF}

Polskie Towarzystwo Filozoficzne działa na podstawie statutu, przyjętego przez Walne Zgromadzenie w styczniu 1994 roku. Siedziba PTF mieści się w Warszawie.

Towarzystwo posiada 22 Oddziały terenowe: w Warszawie, Gdańsku, Kaliszu Katowicach, Krakowie, Lublinie, Łodzi, Poznaniu, Szczecinie, Toruniu, Wrocławiu, Olsztynie, Częstochowie, Kielcach, Cieszynie (wraz z Kołem PTF w Bielsku Białej), Radomiu, Słupsku (zawieszony), Siedlcach, Bydgoszczy, Rzeszowie Zielonej Górze i Opolu.

W 2014 r. Polskie Towarzystwo Filozoficzne liczyło 1049 członków.

Od 2009 r. Polskie Towarzystwo Filozoficzne posiada status organizacji pożytku publicznego (nr 0000029971).

Na dzień 13.02.2015 skład Zarządu Głównego Polskiego Towarzystwa Filozoficznego przedstawia się następująco:

Prezydium ZG PTF

Przewodniczący PTF:

Z-ca przewodniczącego

Skarbnik:

Sekretarz: prof. dr hab. W. Stróżewski prof. dr hab. B. Markiewicz prof. dr hab. J. Stuchliński dr Magdalena Gawin 
Członkowie Zarządu Głównego: prof. Ryszard Wiśniewski, prof. Ryszard Kleszcz, dr hab. Marek Rembierz,

Zastępcy Członków: prof. dr hab. Krzysztof Brzechczyn, dr hab. Krystyna Krauze-Błachowicz, mgr Leszk Garcarz

Główna Komisja Rewizyjna: dr Mariusz Kubiak (przewodniczący), dr Małgorzata Baranowska, dr hab. Andrzej Łukasik, dr Michał Woroniecki

\section{B. Cele statutowe PTF}

Celem Towarzystwa jest uprawianie i krzewienie nauk filozoficznych.

Towarzystwo realizuje swoje zadania przez:

a) prowadzenie wykładów naukowych i popularno-naukowych,

b) odbywanie zebrań naukowo-dyskusyjnych,

c) organizowanie zjazdów naukowych,

d) prowadzenie bibliotek dzieł filozoficznych oraz dzieł pomocnych przy studiowaniu nauk filozoficznych,

e) działalność wydawnicza,

f) reprezentowanie potrzeb nauk filozoficznych wobec władz i społeczeństwa,

g) udział w pracach instytucji międzynarodowych, służących uprawianiu i krzewieniu nauk filozoficznych.

\section{Podstawy finansowe:}

Działania statutowe ZG PTF w 2014 roku były finansowane ze składek członkowskich i środków Olimpiady Filozoficznej. Oddziały PTF dysponują własnymi środkami pochodzącymi ze składek członkowskich. W roku 2014 składka dla profesora i samodzielnych pracowników nauki wynosiła $45 \mathrm{zł}$, dla pozostałych $30 \mathrm{zł}$.

\section{REALIZACJA CELÓW STATUTOWYCH}

\section{DZIAŁALNOŚĆ STATUTOWA}

\section{A. Zarząd Główny PTF}

W roku 2014 odbyły się 4 posiedzenia Zarządu Głównego PTF (31.01.2014, 19.04.2014, 21.05.2014, 21.12.2014). 
Z zaplanowanych na rok 2014 działań udało się zrealizować następujące:

Wspierano dalszą działalność popularyzatorską wśród młodzieży. PTF zorganizował XXVI i pierwszy etap XXVII Olimpiady Filozoficznej oraz - w województwie mazowieckim - Konkurs Filozoficzny dla Gimnazjalistów.

Kontynuowano dotychczasową działalność wydawniczą, w zakresie wydawania „Biuletynu OF”. „Ruch Filozoficzny” nie był wydawany.

Zrealizowano uchwałę Walnego Zgromadzenia PTF z dnia 31.01.2014 r. dotyczącą dostarczenia do MNiSW uchwały w kwestii miejsca filozofii na uniwersytetach w Polsce.

Uregulowano kwestię możliwości korzystania z biblioteki IF UW.

\section{Sekcje i zespoły}

Przy ZG PTF działają następujące sekcje: przy Oddziale PTF w Krakowie działa Zespół Metodologii i Teorii Poznania im. Izydory Dąmbskiej, który zorganizował 3 zebrania naukowe:

dr Leszek Wroński, Czy okresy warunkowe stwierdzają konieczność lub prawdopodobieństwo?

prof. Maciej Witek (Uniwersytet Szczeciński), Funkcja konwencji illokucyjnych z punktu widzenia interakcjonistycznego modelu aktów mowy

prof. Grażyna Borowik, dr Andrzej Kowal, Konwencje w sztuce i medycynie

\section{DZIAŁALNOŚĆ STATUTOWA ODDZIAłÓW PTF}

\section{A. Działalność naukowa}

\section{Sesje, konferencje, seminaria}

Oddział PTF w Bydgoszczy zorganizował następujące sesje: prof. dr hab. Ireneusz Ziemiński (Uniwersytet Szczeciński), Eschatologia Marcela Prousta, prof. dr hab. Ireneusz Ziemiński (Uniwersytet Szczeciński), Kryzys chrześcijaństwa z perspektyzwy filozofa religii, współorganizacja dwóch ogólnopolskich konferencji: Po co filozofia? (Bydgoszcz 6-7 marca); Wybitne kobiety w Szkole Lwowsko-Warszaw- 
skiej (16-17 października). Konferencje odbyły się na Uniwersytecie Kazimierza Wielkiego.

\section{Oddział PTF w Cieszynie i koła PTF w Bielsku-Białej}

Forum Polskiej Myśli Filozoficznej - organizowane przez Polskie Towarzystwo Filozoficzne oraz Collegium Invisibile - odbyło się 18-19 IX 2014 w gmachu I Liceum Ogólnokształcącego im. Mikołaja Kopernika w Bielsku-Białej, uczestniczyli wybitni przedstawiciele wielu akademickich środowisk naukowych, m.in.: prof. dr hab. Jan Woleński, prof. dr hab. Adam Grobler, prof. dr hab. Adam Jonkisz, prof. dr hab. Karol Tarnowski, dr hab. Andrzej Gniazdowski, prof. PAN, dr hab. Wiesław Wójcik, prof. PAN, dr hab. Wojciech Załuski, prof. UJ. Głównym celem konferencji było ukazanie wielości podejmowanych działań przez filozofów: dzielenie się własnymi rezultatami badań, poszukiwanie odpowiedzi na stawiane pytania, analizowanie tekstów źródłowych, uczestniczenie w debatach filozoficznych; łącznie 34 wykłady w części naukowej (ogółem około 140 uczestników, słuchaczami byli też uczniowie i nauczyciele liceum).

WSPÓŁORGANIZACJA KONFERENCJI MIĘDZYNARODOWEJ. Cieszyński Oddział Polskiego Towarzystwa Filozoficznego był współorganizatorem jednej konferencji międzynarodowych (we współpracy polsko-słowackiej): „Disputationes quodlibetales" - „Náboženstvo v situácii 25 rokov po nežnej revolúcii)”. Prešovska univerzita v Prešove, 20 XI 2014.

\section{Oddział PTF w Krakowie}

współorganizował wraz z IF Akademii Ignatianum oraz Zakładem Historii Filozofii IF UJ międzynarodową konferencję After Rawls w dniach 2-3 czerwca, podczas której wygłoszono 18 referatów;

współorganizował wraz z Zakładem Historii Filozofii IF UJ cykl seminariów, pt.: Radykałowie i konserwatyści w epoce Oświecenia:

prof. Władimir Warawa (Państwowy Instytut w Woroneżu), Dimitry Venevitynov: The Birth of Philosophy out of the Spirit of Enlightement (28.03)

prof. Jonathan Israel (Princeton University), Radical Enlightenment and the European Revolutions of the Late Century (13.06)

prof. Joanna Żelazna (UMK), Traktat teologiczno-polityczny - „księga wykuta w piekle" (7.11)

prof. Maciej Chmieliński (UŁ), Kosmopolityczny realizm Oświeceniowej koncepcji Immanuela Kanta (21.11)

dr hab. Przemysław Gut (KUL), Radykalizm filozofii Spinozy i oświeceniowa refleksja nad natura ludzka (5.12) 


\section{Oddział PTF w Łodzi}

zorganizował sesję doktorantów, w trakcie której wygłoszono następujące referaty:

mgr Daniel Maliński (Łódź), Metaforycznie rzecz ujmując, czyli o braku argumentów Mariana Przetęckiego

mgr Piotr Sękowski (Łódź), Krytyka teorii ewolucji oczami ex-kreacjonisty mgr Magdalena Matusiak (Łódź), Jak żyć? - odpowiedź Mariana Przetęckiego,

mgr Tomasz W. Michałowski (Łódź), Koncepcja prawa publicznego w filozofii Immanuela Kanta

mgr Przemysław Wierzbicki (Łódź), Imre Lakatos. O roli klauzuli ceteris paribus w procesie sprawdzania teorii naukowej

\section{Oddział PTF w Opolv}

zorganizował następujące otwarte seminaria:

- 23 stycznia 2014 r, Muzeum Śląska Opolskiego, Otwarte Seminarium PTF, Trzecie spotkanie z cyklu „KONFERENCJA BŁYSKAWICZNA” prof. Adam Grobler dr hab. Grzegorz Francuz, dr Marcin Pietrzak, Przydatność filozofii na różnych etapach życia

- 20 lutego 2014 r., Muzeum Śląska Opolskiego, Otwarte Seminarium PTF, Nie zostanie kamień na kamieniu. Apokalipsa kiedyś i dziś, dr hab. Grzegorz Francuz, dr Piotr Leśniak

- 10 kwietnia 2014 r., Muzeum Śląska Opolskiego, Otwarte Seminarium PTF, Filozofia wiecznie młoda, prof. Adam Grobler, prof.. Tadeusz Olewicz dr Piotr Leśniak

- 8 maja 2014 r., Muzeum Śląska Opolskiego, Otwarte Seminarium PTF, Co to jest terapia filozoficzna?, dr Piotr Leśniak, mgr Magdalena Żołud, prof.. Tadeusz Olewicz

- 9 października 2014, Muzeum Śląska Opolskiego, Otwarte Seminarium PTF, Filozoficzna inauguracja jesieni, dr hab. Grzegorz Francuz, dr Piotr Leśniak, dr Marcin Pietrzak

- 6 listopada 2014, Muzeum Śląska Opolskiego, Otwarte Seminarium PTF, Filozofia jako droga do szczęścia, dr hab. Grzegorz Francuz

- 4 grudnia 2014, Muzeum Śląska Opolskiego, Otwarte Seminarium PTF, Barbórka z punktu widzenia logiki, prof. Adam Grobler

\section{Oddział PTF w Rzeszowie}

współorganizował konferencję Filozofia i literatura, która odbyć się ma w maju 2015 r. 


\section{Oddział PTF w Siedlcach}

seminarium naukowe, Ochrona informacji niejawnych $i$ danych osobowych w systemie bezpieczeństwa państwa (czerwiec 2014), konferencja naukowa: Wspótczesne bezpieczeństwo informacyjne (listopad 2014).

\section{Oddział PTF w Toruniu}

współorganizacja imprez otwartych z cyklu „Czwartki z filozofią" oraz organizacja warsztatów dla młodzieży, współorganizacja konferencji wraz z IF UMK.

\section{Debaty i dyskusje}

\section{Oddział PTF w Lublinie:}

zorganizował dwie debaty pomiędzy Janem Woleńskim i Jackiem Wojtysiakiem na temat: Czy Bóg jest potrzebny do wyjaśnienia świata? oraz pomiędzy Andrzejem Niemczukiem i Arkadiuszem Gutem na temat: Dialog między optymizmem a pesymizmem.

\section{Oddział PTF w Rzeszowie}

zorganizował w dniu 30 marca dyskusję wokół książki Stanisława Gałkowskiego pt. Barbarzyńcy i obywatele. Myślenie polityczne wobec wartości.

\section{Oddział PTF w Siedlcach zorganizował debaty:}

Odyseja madrości - od filozofii do antyfilozofii, słowo wstępne do dyskusji wygłosił ks. dr Grzegorz Stolarski, w odniesieniu do książki Petera A. Redpath'a Odyseja mąrości;

Czy człowiek to moralna matpa? , słowo wstępne do dyskusji wygłosiła dr Ewa Zgolińska, w odniesieniu do książki Fransa de Waal'a Matpy i filozofowie. Skąd pochodzi moralność?;

Kibuc-zrealizowana utopia?, słowo wstępne do dyskusji wygłosiła dr Renata Tarasiuk

Oddział PTF w Warszawie zorganizował następujące dyskusje:

PANel: Filozofia dialogu międzyreligijnego 
W panelu udział wzięli: prof. dr hab. Stanisław Krajewski Instytut Filozofii UW oraz dr Marek Nowak Instytut Filozofii UW. Spotkanie prowadził: mgr Jarosław Jarszak, Zarząd Oddziału Warszawskiego PTF

\section{Wykłady, referaty i prelekcje}

\section{Oddział PTF w Bydgoszczy}

zorganizował następujące odczyty naukowe:

dr Daniel R. Sobota, Co to jest przyroda?,

prof. Ryszard Mordarski, Problem zła - wstęp do ksiażki Petera van Inwagena, „Problem zła. Wykłady im. Gifforda wygłoszone na Uniwersytecie St. Andrews w 2003 roku" (przet. i wstęem opatrzyt R. Mordarski,

dr Marek Pepliński (UG), O dą̇eniach filozofów czyli ile jest filozofii? Próba wskazania przyczyn powstania kontrowersji oraz zasugerowania kierunku wyjśsia,

dr Piotr Cyciura, Filozoficzne pojęcie faktu wobec szczególnej teorii względności Einsteina,

dr hab. Artur Przybysławski, Świadomość w ujęciu filozofii buddyjskiej w ramach nawiązanego kontaktu z Bydgoskim Ośrodkiem Buddyjskim.

\section{Oddział PTF w Cieszynie i Koło PTF w Bielsku-Białej}

ZEBRANIA: 5 spotkań w Cieszynie i 4 spotkania w Bielsku-Białej; razem 9 spotkań.

Wiodąca tematyka referatów:

- filozofia polska w kontekście filozofii europejskiej (w tym też omawiano artykuły do „Studiów z Filozofii Polskiej”);

- nauczanie filozofii;

- filozofia nauki i filozofia matematyki;

- metafilozofia;

- problemy metodologii nauk pedagogicznych;

- aksjologia i antropologia filozoficzna;

- filozofia edukacji, etyka pedagogiczna i koncepcje personalistyczne w pedagogice;

- związki filozofii i etyki społecznej z teorią pracy socjalnej i polityki społecznej. 


\section{Oddział PTF w Częstochowie zorganizował odczyły:}

prof. dr hab. Andrzej Gwóźdź (Uniwersytet Śląski, Nowe media a kino designu,

prof. dr hab. Elżbieta Jung (Uniwersytet Łódzki), Bóg i nauka, Filozofia i teologia w dojrzatym średniowieczu,

dr hab. Gabriela Besler (Uniwersytet Śląski), Tematyka korespondencji naukowej Gottloba Fregego z Bertlandem Russellem w latach 1902-1904,

\section{Oddział PTF w Gdańsku}

zorganizował następujące odczyty i dyskusje :

dr Robert Rogoziecki (Uniwersytet Gdański), Konsumpcja i estetyzacja życia,

doc. dr Marian Pyrz (PTF OG), O metahistoriozofii i aksjomatach geopolityki imperialnej Rosji,

dr Marek Pepliński (Uniwersytet Gdański), Wszechświat-Bóg-umyst-etyka, dr Tomasz Kąkol (Uniwersytet Gdański), Wszechświat-Bóg-umyst-etyka, doc. dr Marian Pyrz (PTF OG), Umyst studenta i jego deformacje w świetle logiki diachronicznej.

\section{Oddział PTF w Katowicach}

zorganizował następujące referaty:

prof. dr hab. Tadeusz Szubka (Uniwersytet Szczeciński), O metafilozoficznych konsekwencjach sporów filozoficznych,

ks. prof. dr hab. Michał Dróżdż (Uniwersytet Papieski w Krakowie), Spór o normatywność w etyce mediów,

dr Ryszard Miszczyński (Akademia im. Długosza w Częstochowie), Intuicyjny formalizm Stanisława Leśniewskiego,

dr Agnieszka Woszczyk (Uniwersytet Śląski), Filozofia i coaching. Na granicy między teoria a praktyka?,

prof. Kurt Walter Zeidler (Uniwersytet w Wiedniu), Philosophy of Science.

\section{Oddział PTF w Kielcach}

zorganizował następujące odczyty naukowe:

prof. Lucyna Wiśniewska-Rutkowska, Krytyka marksizmu w „Tygodniku Warszawskim",

dr Paweł Koza, Metoda metapolityczna w teorii sprawiedliwości Johna Rawlsa. 


\section{Oddział PTF w Krakowie}

zorganizował następujące odczyty naukowe:

prof. Władysław Stróżewski, Piotr Skarga o madrości,

prof. Władimir Warawa (Państwowy Uniwersytet w Woroneżu), Języki filozofii rosyjskiej (zwiazki literatury i filozofii w kulturze rosyjskiej), wykład tłumaczony z rosyjskiego,

prof. Wojciech Sady (Uniwersytet Pedagogiczny w Krakowie), Od Kopernika do Galileusza.

\section{Oddział PTF w Lublinie}

zorganizował następujące odczyty naukowe:

prof. Damiana Leszczyńskiego (Uniwersytet Warmińsko-Mazurski), Realizm, racjonalizm, sceptycyzm,

prof. Józefa Dębowskiego (Uniwersytet Warmińsko-Mazurski), O obiektywnosci prawdy i jej podstawach ontycznych.

\section{Oddział PTF w Łodzi}

zorganizował następujące referaty:

prof. Marek Gensler (Łódź), Waltera Burleya komentarz do Arystotelesa "Ksiag o snach",

prof. Ryszard Kleszcz (Łódź), Kazimierz Twardowski o kształceniu filozofów, dr Tomasz Śliwiński (Łódź), Człowiek niewidzialny dla rozumu - w poszukiwaniu prawdziwego człowieka Kartezjusza,

dr Krzysztof Kędziora (Łódź), Stanisława Brzozowskiego spory z pozytywizmem.

\section{Oddział PTF w Olsztynie:}

zorganizował jeden odczyt naukowy.

\section{Oddział PTF w Radomiu:}

prof. dr hab. Andrzej Łukasik, Jak istnieje czas?, dr Andrzej Niemczuk, Wolność człowieka w świetle egzystencjalizmu, prof. dr hab. Jan Woleński, Filozofia polska w perspektywie międzynarodowej.

\section{Oddział PTF w Warszawie}

zorganizował następujące wykłady:

WYKŁAD: Etyka lekarska z perspektywy lekarza 
Prelegent: prof. dr hab. Tomasz Pasierski, kierownik Zakładu Bioetyki i Humanistycznych Podstaw Medycyny Warszawskiego Uniwersytetu Medycznego,

ReFERAT: Izaak Newton - między alchemią a filozofią przyrody

Referent: dr hab. Janusz Sytnik-Czetwertyński profesor Uniwersytetu Kazimierza Wielkiego w Bydgoszczy,

Referat: Metodologiczne wyzwania filozofii eksperymentalnej. Analiza na wybranych przykładach badań filozoficzno-eksperymentalnych.

Referent: mgr Adrian Ziółkowski, doktorant IF UW,

Prelekcja: Zmysłowość a poznanie dyskursywne w filozofii I. Kanta

Prowadzący: mgr Piotr Kozak doktorant Instytutu Filozofii UW,

REFERAT: O argumencie z implikatury konwersacyjnej

Referent: dr Tomasz Puczyłowski, Zakład Logiki Instytutu Filozofii UW, PreleKcja: Ogród jako przedmiot estetyki

Prelegent: dr Mateusz Salwa Zakład Estetyki Instytutu Filozofii UW

\section{Oddział PTF we Wrocławiu}

współorganizował następujące odczyty naukowe :

dr Katharina Bauer (Ruhr-UniversitatBochum, Niemcy), I just have to do this - Dimensions of practical necessity, mgr Piotr Rudkowski, Problem wyjaśniania w teologii,

dr Natalia Artmenko (Uniwersytet w Sankt Petersburgu), Martin Heideggers "Phänomenologische Interpretationen zu Aristoteles" (sog. Natorp-Bericht von 1922) als Prototyp von "Sein und Zeit",

dr Łukasz Mścisławski (Politechnika Wrocławska), Struktury matematyczne a fizyka - nowe perspektywy,

dr Katarzyna Kuczyńska (Wrocławskie Centrum Doskonalenia Nauczycieli), Filozofia - pomaga czy szkodzi polskiej szkole?

\section{B. Działalność popularyzatorska}

\section{Charakterystyka ilościowa}

W 2014 roku na zebraniach i konferencjach zorganizowanych przez PTF wygłoszono (informacje z 20 oddziałów) prelekcji i odczytów naukowych.

\section{Ogólna charakterystyka wykładów}

Prelegenci

Większość odczytów na zebraniach plenarnych PTF wygłaszali jego członkowie. 
Podobnie jak w latach ubiegłych Oddziały PTF wykorzystują pobyty zagranicznych gości.

Tematyka

W roku 2014 tematyka spotkań obejmowała problemy charakterystyczne dla poszczególnych dyscyplin filozoficznych, ze szczególnym uwzględnieniem aktualnych problemów związanych z rozwojem nauki, sytuacją społeczno-polityczną i znaczeniem edukacji filozoficznej.

\section{Działalność popularyzatorska dla młodzieży}

Członkowie PTF prowadzili konsultacje dla uczestników Olimpiady Filozoficznej, brali także udział w pracach związanych z jej przeprowadzeniem (przygotowanie programów, tematów, sprawdzanie prac).

\section{Oddział PTF w Cieszynie i koło w Bielsku-Białej}

I Letnia Szkoła Nauk Filozoficznych i Społecznych im. prof. Jana Szczepańskiego - Cieszyn - Ustroń, od 08.09.2014 (poniedziałek) do 11.09.2014 (czwartek); łącznie 22 wykłady w części naukowej, a także odbyły się warsztaty i wykłady dla młodzieży i nauczycieli ze szkół Ziemi Cieszyńskiej (ogółem około 300 uczestników). Oddział włączył się w prace nad lokalną inicjatywą powołania „Letniej Szkoły Nauk Filozoficznych i Społecznych". Rada Powiatu Cieszyńskiego i Rada Miasta Ustroń - na wspólnej i otwartej sesji 11 X 2013 r. - przyjęły oświadczenia, że „realizując marzenie prof. Jana Szczepańskiego zawarte w „Dziennikach z lat 1933-1945”, a także dla uczczenia jego pamięci” popierają inicjatywę powołania Letniej Szkoły Nauk Filozoficznych i Społecznych. Stwierdzono też, iż „zadaniem szkoły będzie upowszechnianie spuścizny intelektualnej profesora, wielkiego uczonego pochodzącego z Ziemi Cieszyńskiej". Letnia Szkoła Nauk Filozoficznych i Społecznych będzie nosić - jak uznał komitet organizacyjny - imię prof. Jana Szczepańskiego (1913-2004), gdyż to on w swych „Dziennikach” na początku II wojny światowej (zapis z 8 I 1940) wysunął ideę powołania w Ustroniu takiej szkoły, jako stałego elementu życia kulturalnego na Śląsku Cieszyńskim: „Będziemy mieli w Ustroniu dwie rzeczy cenne: bibliotekę i muzeum. A może uda nam się zrealizować kiedyś jeszcze jedno marzenie: wolną szkołę nauk filozoficznych i społecznych w Ustroniu".

\section{Oddział PTF w Gdańsku}

członkinie Oddziału (mgr Krystyna Bembenek, dr Iwona Krupecka) współorganizowały i prowadziły warsztaty filozoficzne dla licealistów z woj. pomorskiego. 


\section{Oddział PTF w Łodzi}

sprawował mecenat nad Młodzieżową Akademią Filozoficzną.

\section{Oddział PTF w Radomiu}

uczestniczył w przygotowaniach do V Festiwalu Filozofii OKNA im. Leszka Kołakowskiego

\section{Oddział PTF w Toruniu}

organizacja odczytów w szkołach

\section{WSPÓtPRACA NAUKOWA}

\section{Współpraca krajowa}

Oddziały PTF pozostawały w dobrych kontaktach z Wydziałami Filozoficznymi miejscowych Uniwersytetów, a także Oddziałami PAN. Ponieważ przyznane dotacje nie pozwalają na samodzielnie zorganizowanie konferencji czy seminarium, Oddziały PTF podejmowały także współpracę z innymi instytucjami naukowymi m.in. z Akademią Podlaską

\section{Wspótpraca zagraniczna}

PTF jest członkiem Międzynarodowej Federacji Towarzystw Filozoficznych. Co roku polscy reprezentanci uczestniczą w Międzynarodowej Olimpiadzie filozoficznej.

\section{DZIAŁALNOŚĆ WYDAWNICZA}

W roku 2014 nie wyszedł „Ruch Filozoficzny” ze względu na brak dofinansowania z MNiSW.

Zarząd Główny Polskiego Towarzystwa Filozoficznego wydał także "Biuletyn Olimpiady Filozoficznej" nr 44 i 45 oraz broszurę z materiałami pokonferencyjnymi, pt.: Filozofia jako sztuka pisemnej wypowie$d z i$.

Materiały Olimpiady Filozoficznej oraz komunikaty ZG PTF umieszczane były również na stronach internetowych pod adresem http:// www.ptfilozofia.pl 


\section{Oddział PTF w Bydgoszczy}

wydano kolejne tomy kwartalnika „Filo-Sofija”, nr 24, 25/I i 25/II oraz nr 26, nr 27/I i 27/II

Oddział PTF w Cieszynie wydał:

A. Wydawnictwa promowane w roku 2014:

"Studia z Filozofii Polskiej". Tom VIII.

Redakcja naukowa: Marek Rembierz, Krzysztof Śleziński. Kraków-Bielsko-Biała 2013 (ukazało w Wydawnictwie Scriptum), ISSN 1897-8584, stron 330 .

Wydawcą tej serii jest Polskie Towarzystwo Filozoficzne Oddział w Cieszynie (dotychczas wraz Instytutem Teologicznym w Bielsku-Białej). Prace organizacyjne nad tą serią - prowadzone w ramach działalności Polskie Towarzystwo Filozoficzne Oddział w Cieszynie - to także rozbudowanie struktury "Studiów” oraz zaproszenie do współpracy ze "Studiami” kolejnych autorów i członków Rady Programowej "Studiów".

B. Wydawnictwa przygotowane do druku:

„Studia z Filozofii Polskiej”. Tom IX. Około 300 stron.

C. W przygotowaniu redakcyjnym:

"Studia z Filozofii Polskiej". Tom X. Około 300 stron.

Oddział PTF w Bydgoszczy wraz z Komisją Filozofii Bydgoskiego Towarzystwa Naukowego wydał 4 numery kwartalnika filozoficznego pt.: Filo-Sofija. Wydano w tym $\mathrm{m}$. in. numery tematyczne dotyczące idei filozoficznych Jerzego Kmity oraz podwójny numer dotyczący filozofii Władysława Tatarkiewicza.

\section{Oddział PTF w Siedlcu}

„Utopia obecna - nieobecna”, red. dr Ewa Zgolińska (w druku)

Oddział PTF we Wrocławiu kontynuował współpracę z czasopismem filozoficznym ,'Studia Philosophica Wratislaviensia"

Ponadto członkowie PTF współpracują z wieloma czasopismami filozoficznymi tak w Polsce, jak i zagranica.

\section{BIBLIOTEKA I ARCHIWUM PTF}

Zbiory Biblioteki PTF w 2014 r. liczyły 13722 pozycji. 
156 Sprawozdanie z działalności Polskiego Towarzystwa Filozoficznego w 2015 roku

Biblioteka PTF, którą kieruje Dyrektor Aleksandra Łabuńska mieści się przy Bibliotece Wydziału Filozofii i Socjologii UW. Oprócz książek gromadzi także czasopisma.

W roku 2014 na jej zawartość składało się 8756 książek oraz 277 tytułów czasopism - ubyło 1 tyt. (2076 woluminów i 3116 zeszytów) a także zbiory specjalne, w skład których wchodzą starodruki (36 pozycji) i mikrofilmy (83 pozycje).

Kuratorem Archiwum PTF jest prof. dr hab. Jacek J. Jadacki. 